\title{
PET radiopharmaceuticals in Europe: current use and data relevant for the formulation of summaries of product characteristics (SPCs)
}

\author{
G.-J. Meyer ${ }^{1}$, S.L.Waters ${ }^{2}$, H.H. Coenen ${ }^{3}$, A. Luxen ${ }^{4}$, B. Maziere ${ }^{5}$, B. Langstrôm ${ }^{6}$ \\ 1 Abteilung Nuklearmedizin. Medizinische Hochschule Hannover, D-30623 Hannover, Germany \\ ${ }^{2}$ MRC Clinical Sciences Centre, Hammersmith Hospital, Ducane Road, London W12 ONN, England \\ ${ }^{3}$ Klinik fur Nuklearmedizin, Universitâtsklinik Essen, Hufelandstr. 55, D-45122 Essen, Germany \\ ${ }^{4}$ Centre de Recherces du Cyclotron, Université de Liège, B-4000 Liège 1, Belgium \\ ${ }^{5}$ CEA Departement de Recherche Medicale, SHFJ, 4 Place de General Leclerc, F-91406 Orsay, France \\ ${ }^{6}$ Uppsala University PET Center, U.A.S., S-75185 Uppsala, Sweden
}

\begin{abstract}
The increasing use of radiopharmaceuticals for positron emission tomography (PET) has come to the attention of regulatory bodies. In order to help authorities in all aspects, the EANM has formed a task group for licensing PET radiopharmaceuticals; this group has surveyed the use of these compounds in Europe by a questionnaire. The number of PET centres that responded to the questionnaire was 26 , which included more than $90 \%$ of the larger European PET centres. The survey showed that 2-[ $\left.{ }^{[8} \mathrm{F}\right]$ fluoro-2-deoxyglucose is by far the most important PET radiopharmaceutical with more than 200 applications per week, followed by $\left[{ }^{\mathrm{ls}} \mathrm{O}\right]$ water,

$\left[{ }^{5} \mathrm{O}\right]$ carbonmonoxide, $\left.\mathrm{f}^{13} \mathrm{~N}\right]$ ammonia, $\left[{ }^{\mathrm{n}} \mathrm{C}\right]-\mathrm{L}-\mathrm{methio-nine}$, and L-6- $\left[{ }^{18} \mathrm{~F}\right]$ fluoro-DOPA. More than 25 other PET radiopharmaceuticals are in regular use, however, at rather low application frequencies. The data were used by the European Pharmacopoeia Commission for its priority rating for requesting the formulation of monographs. Since it is likely that group registrations will be issued by authorities for the PET radiopharmaceuticals, relevant data on toxicity and dosimetry for the formulation of summaries of product characteristics have been collected by the task group as well.
\end{abstract}

\section{Introduction}

The present, use of PET radiopharmaceuticals (PET RPs) in Europe has prompted attention by the medicinal products regulatory bodies at both national and European levels. In 1993 the European Pharmacopoeial Commission (EPC) decided to initiate the introduction of monographs for PET RPs, namely for 2- $\left[{ }^{18} \mathrm{~F}\right]$ fluoro-2deoxy-D-glucose $\left(2-\left[{ }^{18} \mathrm{~F}\right] \mathrm{FDG}\right)$ and $\left[{ }^{15} \mathrm{O}\right]$-water. In order to stress these efforts, the EPC decided to create a group of PET specialists, associated with Expert Group No. 14, who would prepare monographs for the European Pharmacopoeia (Eur. Ph.) for the more commonly used PET RPs. This group of PET specialists has been recruited mainly from the members of the EANM Task Group for Licensing of PET Radiopharmaceuticals. In order to establish a sound basis for any priority rating for new monographs, the EANM Task Group produced a questionnaire to determine the frequency of use of PET RPs. This was sent to all PET users in Europe in 1994. The results of this questionnaire were used for the latest priority rating by the EPC in autumn 1994, which has now ordered the preparation of monographs for a further four PET RPs, namely $\left[{ }^{15} \mathrm{O}\right]$ carbon monoxide, $\left[{ }^{13} \mathrm{~N}\right]$ ammonia, $\left[{ }^{\pi} \mathrm{C}\right]$-L-methionine, and L-6- $\left[{ }^{18} \mathrm{~F}\right]$ fluoro-DOPA.

\section{Current use of PET radiopharmaceuticals}

The results of the questionnaire are summarized in Table 1 and Figs. 1-6. The number of PET installations in Europe is shown in Table 1 and Fig. 1.

These data include PET installations that are already in operation and planned sites that have been carefully chosen for inclusion, using information from colleagues in the field. The list of the installations includes the number of PET cameras and accelerators operated at the site.

Except in Germany, nearly all the installations operate their own accelerators. In Germany the situation is somewhat different, because several PET camera locations are provided with tracers from other centres. Experience with this so-called satellite concept is promising and has significantly stimulated the clinical use of PET investigations. It is likely that this development will continue, provided that the availability of PET tracers improves. It is also probable that with expansion of this satellite concept, the fraction of installations that operate their own accelerator will decline below the present $50 \%$. With the improvement in the regulatory situation for the production and the distribution of PET RPs, and an increasing interest of the pharmaceutical industry, chances are good for the further development of PET. 
Table 1. PHT Installations in Europe

\begin{tabular}{|c|c|c|c|c|c|}
\hline Country & $\begin{array}{l}\text { PET location: } \\
\text { working/planned }\end{array}$ & Institution & $\begin{array}{l}\text { Number of } \\
\text { cameras }\end{array}$ & $\begin{array}{l}\text { Number of } \\
\text { accelerators }\end{array}$ & $\begin{array}{l}\text { Questionnaire } \\
\text { response }\end{array}$ \\
\hline \multirow[t]{35}{*}{ Germany (D) } & Working & & & & \\
\hline & Aachen & Univ./Nucl. Med. & 1 & - & $\mathbf{X}$ \\
\hline & Berlin & Univ./Nucl. Med. & 1 & 1 & - \\
\hline & Bonn & Private/Univ. & 1 & & $\mathbf{X}$ \\
\hline & Dusseldorf & Univ./Nucl. Med. & I & - & $\mathbf{X}$ \\
\hline & Essen & Univ./Nucl. Med. & 1 & 1 & $\mathbf{X}$ \\
\hline & Frankfurt & Private/Univ. & 1 & - & - \\
\hline & Freiburg & Private/Univ. & 1 & - & - \\
\hline & Hamburg & Univ./Nucl. Med. & 1 & 1 & $\mathbf{X}$ \\
\hline & Hamburg & Hosp./Nucl. Med. & 1 & - & $\mathbf{X}$ \\
\hline & Hannover & Univ./Nucl. Med. & 1 & 1 & $\mathbf{X}$ \\
\hline & Heidelberg & DKFZ & 1 & 1 & $\mathbf{X}$ \\
\hline & Jiilich & KFA & 2 & 2 & $\mathbf{X}$ \\
\hline & Cologne & Univ./Neurol. & 2 & 1 & $\mathbf{X}$ \\
\hline & Munich & Univ./Nucl. Med. & 1 & 1 & $\mathbf{X}$ \\
\hline & Munich & Private & 1 & - & - \\
\hline & Münster & Univ./Nucl. Med. & 1 & - & - \\
\hline & Ocynhauscn & Heart Center & 1 & 1 & $\mathbf{X}$ \\
\hline & Rossendorf & FZR & 1 & 2 & - \\
\hline & Tübingen & Univ./Nucl. Med. & 1 & 1 & $\mathbf{X}$ \\
\hline & UIm & Univ./Nucl. Med. & 1 & 1 & $\mathbf{X}$ \\
\hline & Wiesbaden & Private & 1 & 1 & $\mathbf{X}$ \\
\hline & Wiesbaden & Private & 1 & - & - \\
\hline & Sum working $D$ & 22 & 24 & 15 & 15 \\
\hline & Planned & & & & \\
\hline & Göttingen & Univ./Nucl. Med. & 1 & - & \\
\hline & Halle & Univ./Nucl. Med. & 1 & - & \\
\hline & Hannover & Private & 1 & - & \\
\hline & Jena & Univ./Nucl. Med. & 1 & - & \\
\hline & Leipzig & Univ./Nucl. Med. & 1 & 1 & \\
\hline & Magdeburg & Univ./Nucl. Med. & 1 & - & \\
\hline & Mainz & Univ./Nucl. Med. & 1 & 1 & \\
\hline & Würzburg & Univ./Nucl. Med. & 1 & - & \\
\hline & Sum planned D & 8 & 8 & 2 & \\
\hline & Sum overall D & 30 & 32 & 17 & \\
\hline \multirow[t]{9}{*}{ Belgium (B) } & Working & & & & \\
\hline & Brussels & Univ./Nucl. Med. & 1 & 1 & $\mathbf{X}$ \\
\hline & Ghent & Univ./Nucl. Med. & 1 & 1 & $\mathbf{X}$ \\
\hline & Leuven & Univ./Nucl. Med. & 1 & 1 & - \\
\hline & Liege & Univ./PET Center & 1 & 1 & $\mathbf{X}$ \\
\hline & Louvain La Neuve & Univ./Nucl. Med. & 1 & 1 & - \\
\hline & Sum Working B & 5 & 5 & 5 & 3 \\
\hline & Planned & - & - & - & \\
\hline & Sum overall B & 5 & 5 & 5 & \\
\hline \multirow{7}{*}{$\begin{array}{l}\text { United Kingdom } \\
\text { (UK) }\end{array}$} & Working & & & & \\
\hline & Aberdeen & Univ. & 1 & 1 & - \\
\hline & Cambridge & Univ./Nucl. Med. & 1 & 1 & - \\
\hline & London & MRC/Hammersmith & 4 & 2 & $\mathbf{X}$ \\
\hline & London & St. Thomas Hospital & 1 & 1 & - \\
\hline & London & Royal Marsden Hosp. & 1 & - & - \\
\hline & Sum working $G B$ & 5 & 8 & 5 & 1 \\
\hline
\end{tabular}




\section{Planned}

London

Queen's Square FIL

Sum overall $G B$

6

10

\begin{tabular}{|c|c|c|c|}
\hline \multirow[t]{10}{*}{ Italy (I) } & \multicolumn{3}{|l|}{ Working } \\
\hline & Milan & S. Raffaele/Nucl. Med. & 1 \\
\hline & Milan & Univ./Nucl. Med. & ] \\
\hline & Naples & Univ./Nucl. Med. & 1 \\
\hline & Pisa & Univ./Nucl. Med. & 1 \\
\hline & Sum working I & 4 & 4 \\
\hline & $\begin{array}{l}\text { Planned } \\
\text { Bologna }\end{array}$ & IMv/Nucl. Med & 1 \\
\hline & Rome & Univ./Nucl. Med. & 1 \\
\hline & Sum Planned I & & 2 \\
\hline & Sum overall I & 6 & 6 \\
\hline
\end{tabular}

France $(\mathrm{F})$

Working

Caen

Lyon

CEA/CYCEKON

Orsay

CEA/CERMEP

Sum working $F$

CEA/SHFJ

Planned

Toulouse

Sum overall $F$

Univ./Nucl. Med.

4

X

$-$

$\overline{\mathbf{x}}$

$\mathbf{X}$

2

1

6

Netherlands (NL) Working

Groningen

Univ. PET Centre

$\mathbf{X}$

Planned

Amsterdam

Univ. PET Centre

Eindhoven

Univ. PET Centre

Leiden

Univ./Nucl. Med.

Sum planned NL

3

Sum. overall NL 4

X

X

$\mathbf{X}$

2

Switzerland (CH) Working

Villigen

PSI

Zürich

Univ./Nucl. Med.

Sum working $\mathrm{CH}$

2

X

Planned

Basel

Geneva

Univ./Nucl. Med.

Sum planned $\mathrm{CH}$

Univ./Nucl. Med.

Sum overall $\mathrm{CH}$

2

Working

Sweden (S)

Stockholm

Uppsala

Sum working $S$

PF/r Centre

Univ. PET Centre

$\overline{\mathbf{X}}$

Austria (A) Working

Vienna

Planned

Graz

Innsbruck

2

Sum planned A

Univ./Nucl. Med.

Univ./Nucl. Med.

Univ./Nucl. Med.

2

Finland

Working

Turku

Univ. PET Centre

1

2

X

Planned

Helsinki 
Denmark Working

$\begin{array}{lllcr} & \begin{array}{l}\text { Aarhus } \\ \text { Planned } \\ \text { Copenhagen }\end{array} & \text { Univ. PET Centre } & 1 & 1 \\ \text { Spain } & \text { Univ. PET Centre } & 1 & 1 \\ & \text { Madrid } & & \\ \text { Portugal } & \text { Planned } & \text { Univ./Nucl. Med. } & 1 & 1 \\ & \text { Lisbon } & & 1 \\ \text { Poland } & \text { Planned } & \text { Univ./Nucl. Med. } & 1 \\ & \text { Warsaw } & & & 1 \\ \text { Norway } & \text { Planned } & \text { Univ./Nucl. Med. } & 1 & 1 \\ & \text { Oslo } & \text { Univ. PET Centre } & 1 & 1\end{array}$

DKFZ: Deutsches Krebsforschungszentrum (German Cancer Research Center); KFA: Forschungsanlage Jiilich (Research Center Julich); FZR: Forschungszentrum Rossendorf (Research Center Rossendorl); MRC: Medical Research Council; FIL: Functional Imaging Laboratory; CEA: Commissariat à l'énergie atomique (Atomic Energy commission); CYCERON: Cyclotron Biomedical de Caen; CERMEP: Cyclotron de Hôpital Neuro-Cardiologique, SHFJ: Service Hopital Frederic Joliot

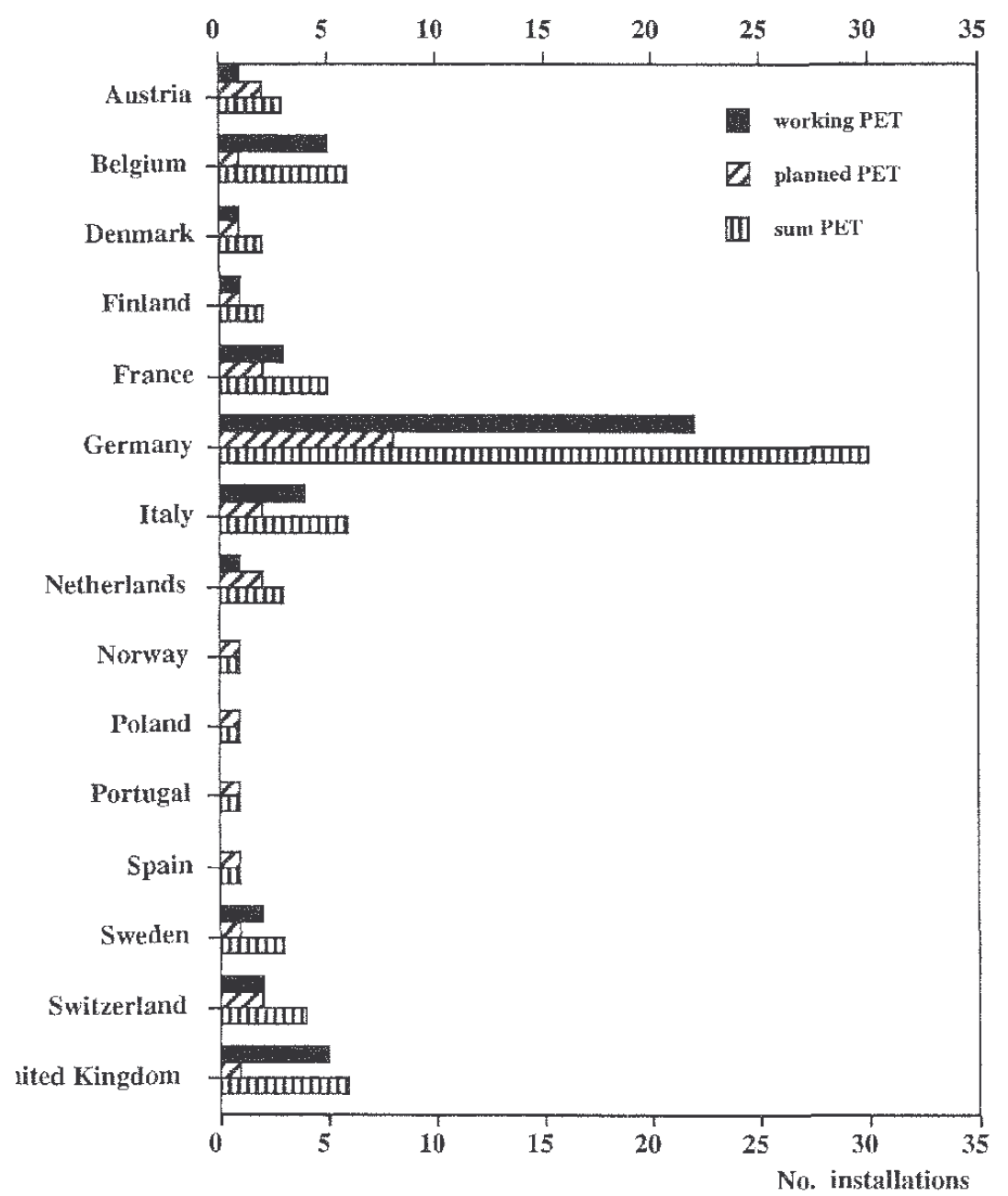

Fig. 1 PET installations in Europe

The overall frequency of use of PET RPs is shown in Figs. 2 and 3. These data have been collected from the 26 PET installations ( $53 \%$ of the total) that responded to our questionnaire, which included $90 \%$ of all the larger PET centres. Our personal knowledge about the other centres justifies the conclusion that the relative frequency of the use of the radiopharmaceuticals would not be shifted significantly if all the centres had responded. Most of 
the centres that have not responded are smaller installations, which have only recently begun their operation. The Task Group is well aware that any rating of the importance of the individual PET RPs is difficult and may lead to misinterpretations in one or the other case. This is unavoidable in terms of the clinical and/or research weighting factor which individual PET groups might assign to certain PET RPs. Neglecting such weighting factors, and from a European Pharmacopoeia point of view, which would give additional importance to those compounds used by more centres, the Task Group has multiplied the overall number of studies by the number of centres using these compounds on a regular basis. It is well understood that this enlarges the "weight" of compounds used by more centres dramatically. A logarithmic scale is necessary to view the result (Fig. 4). In order not to deal with numbers smaller than 1 for compounds used at a very low frequency, a graph factor of 10 is included. The resultant graph is given in Fig. 4.

It can be seen from the Figs. 2-4 that all PET installations in Europe use 2- $\left[{ }^{18} \mathrm{~F}\right] \mathrm{FDG}$ with a total frequency of around 200 studies per week. This is followed by the use of $\left[{ }^{15} \mathrm{O}\right]$ water. The high frequency of its use is partly due to its application in brain activation studies. On the other hand, its use is limited because of its short half-life to those centres possessing their own accelerator.

Only half of all the centres having their own accelerator produce $\left[{ }^{13} \mathrm{~N}\right] \mathrm{ammonia}$, which follows in third place, according to the frequency of use, and in fourth place when multiplied by the number of regular producers. This very important group of tracers also includes $\left[{ }^{15} \mathrm{O}\right]$ carbon monoxide, $\left[{ }^{11} \mathrm{C}\right]$ methionine, $\left[{ }^{15} \mathrm{O}\right]$ oxygen, and L-6$\left[{ }^{\mathrm{ls}} \mathrm{F}\right]$ fluoro-DOPA; $\left.\mathrm{L}^{\pi} \mathrm{C}\right]$ acetatc, [O-methyl- $\left.{ }^{\mathrm{u}} \mathrm{C}\right]$ raclopride, and $\left.\mathrm{p}^{8} \mathrm{~F}\right]$ fluoro-3-N-alkyl-spiperones (FESP) might also be considered among the very important tracers.

All other PET RPs are used by one to three centres only. Three or four tracers of the group labelled important in Fig. 4 are expected to increase in use in the next few years.

The frequency of use of all other PET-RPs is about $10 \%$ only of that for $2-\left[{ }^{18} \mathrm{~F}\right] \mathrm{FDG}$, and it is expected that this relationship will remain basically unchanged in the near future, despite any uncertainties regarding the increase in PET installations.

The number of tracers produced and used on a regular basis varies according to the research capabilities of the PET centres. As shown in Fig. 5, more than ten tracers are available from three centres, and five of the PET centres provide seven to nine tracers on a regular basis. Mid-size centres provide four to six tracers on a regular basis, and small centres use two to three tracers only. Groups that do not operate an accelerator of their own are limited to the use of 2- $\left[{ }^{18} \mathrm{~F}\right] \mathrm{FDG}$ and possibly one or two research products, especially if they are located close to a competent research centre. It is worth mentioning that the centres providing the largest number of different tracers are not necessarily the ones with the largest number of overall studies per week.

Currently only two PET centres provide up to 50 patient studies per week (Fig. 6). It is expected, however, that this number will be reached by more groups in the coming years as more PET users concentrate on clinical studies rather than on research.

Since the information given by the individual institutions does not allow any rating in terms of the quality of their work, and since the goals of the institutions with respect to clinical work and research are quite different, all data have been rendered anonymous.

In order to help the expansion of PET as a clinical utility, the availability of the tracers and especially of 2$\left[{ }^{18} \mathrm{~F}\right] \mathrm{FDG}$ has to be improved. As a prerequisite for this, the legal basis for its production and distribution has to be laid, and the goal of this EANM Task Group was to assist the legal bodies in this task.

The preparation of monographs for inclusion in the Eur. Ph. is a first step in this process. In addition, the Task Group decided to compile data for the more frequently used tracers, which would serve as a source of information for the formulation of summaries of product characteristics (SPCs) and subsequent licensing of these products by individual national authorities. Although the requirements by individual authorities may vary amongst the member states, we are confident that the basic product characteristics reported here are not in question. 


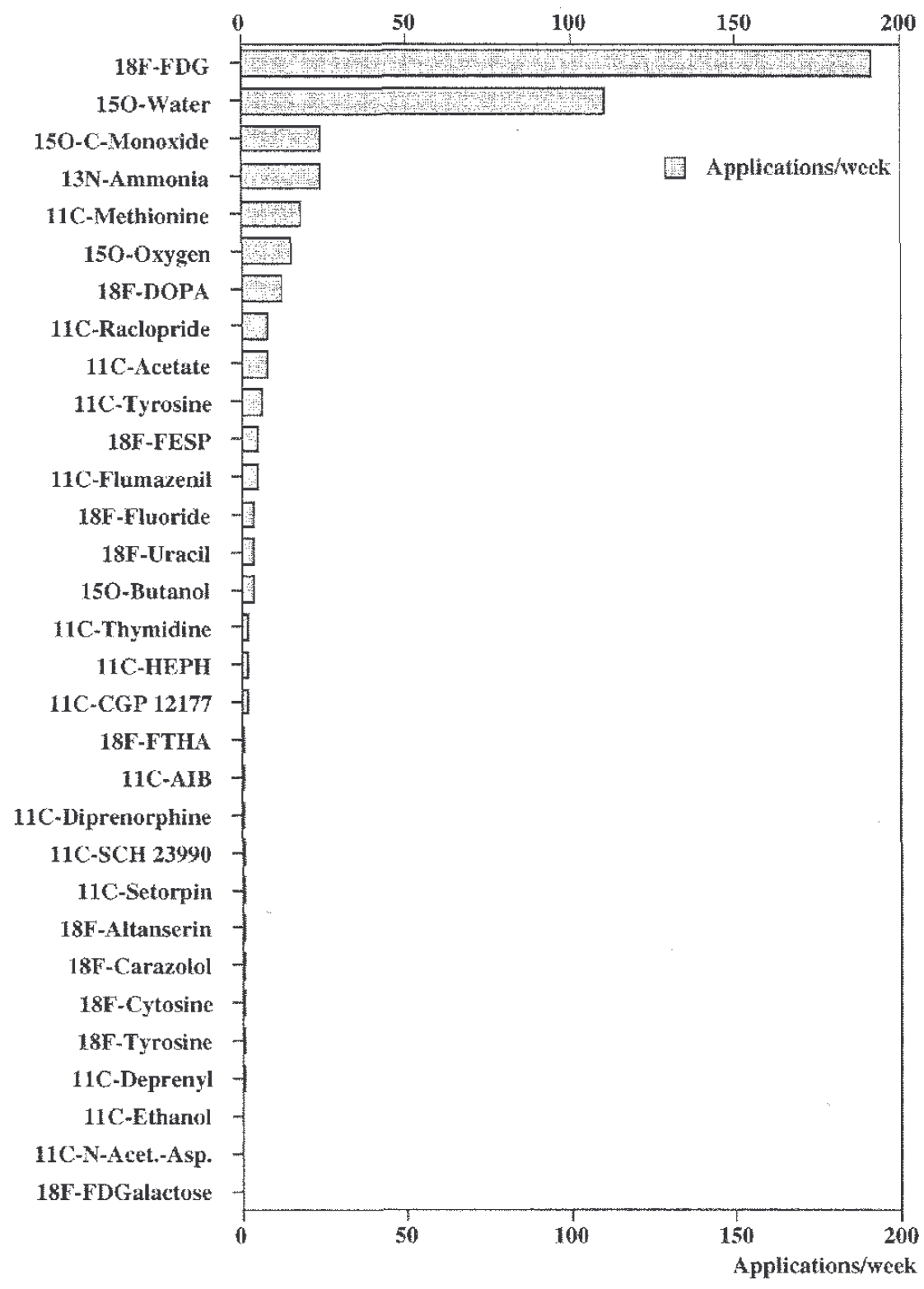

Fig. 2 Frequency of applications of PET tracers 


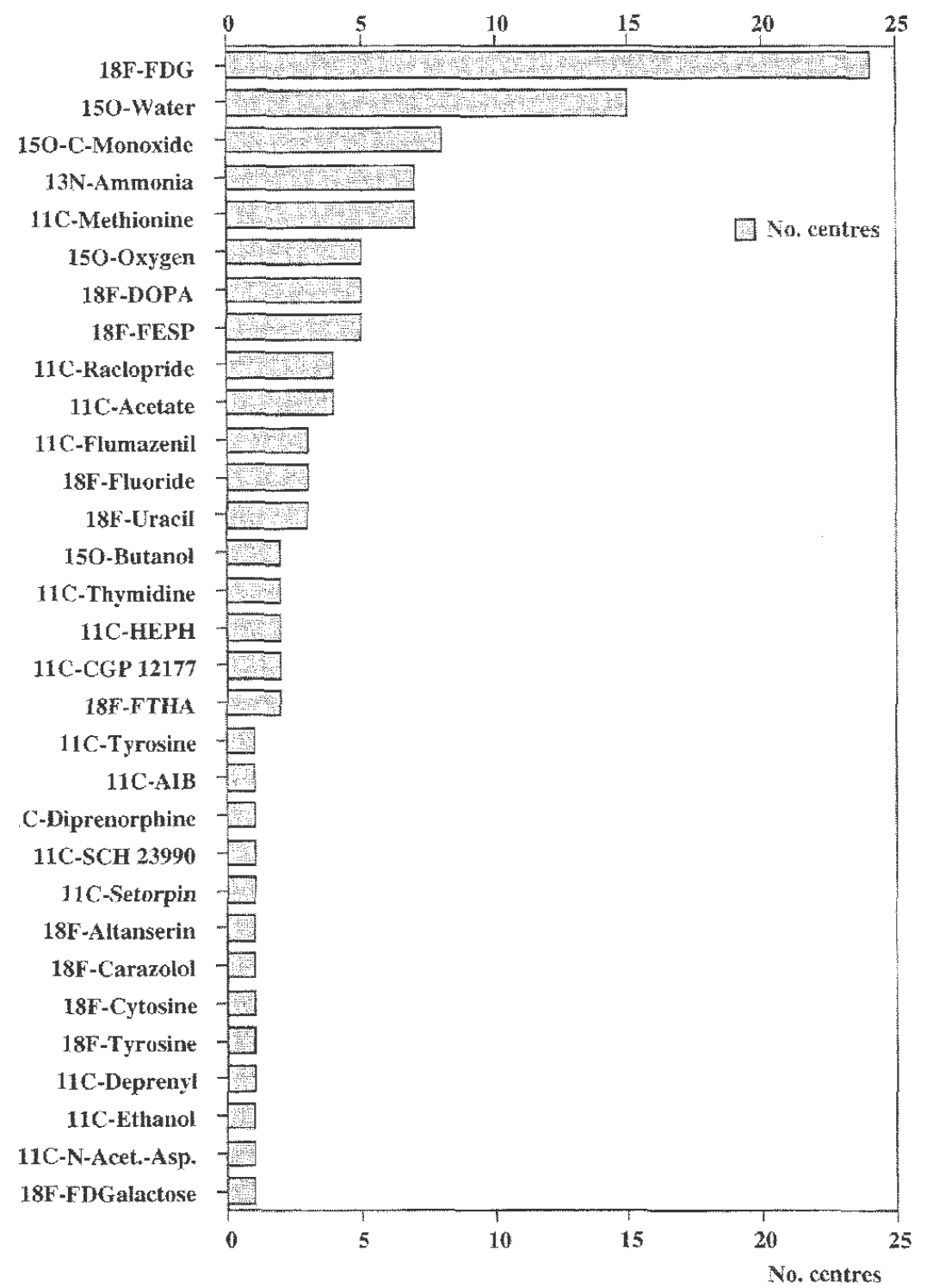

Fig. 3 Production of PET radiopharmaceuticals 


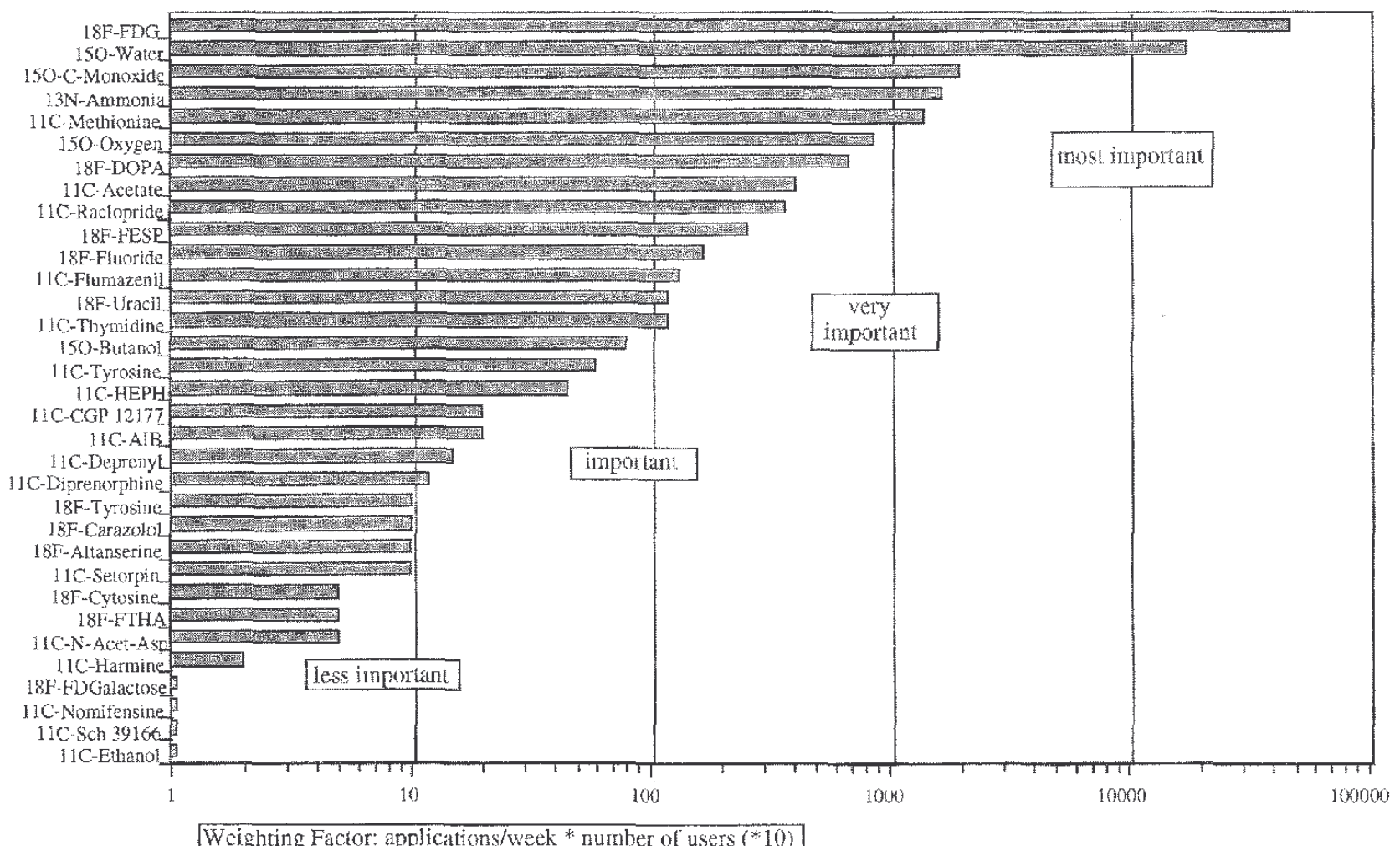

Fig. 4 Relative importance of PET radiopharmaceuticals in Europe

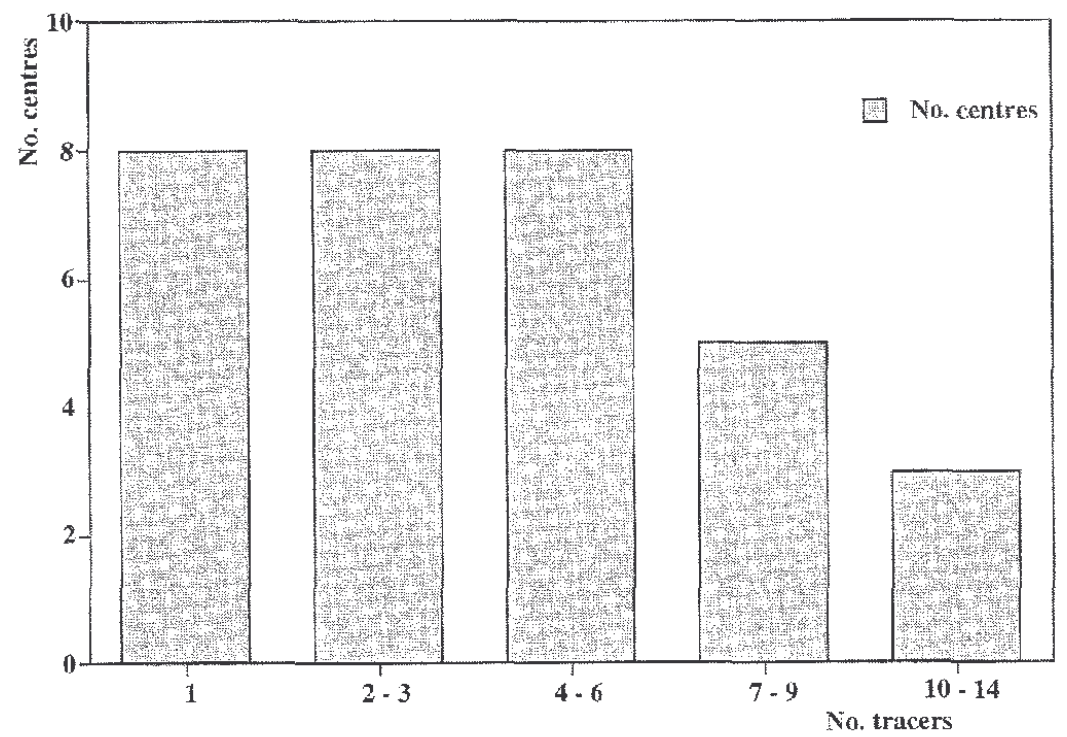

Fig. 5 Number of PET installations using different tracers 


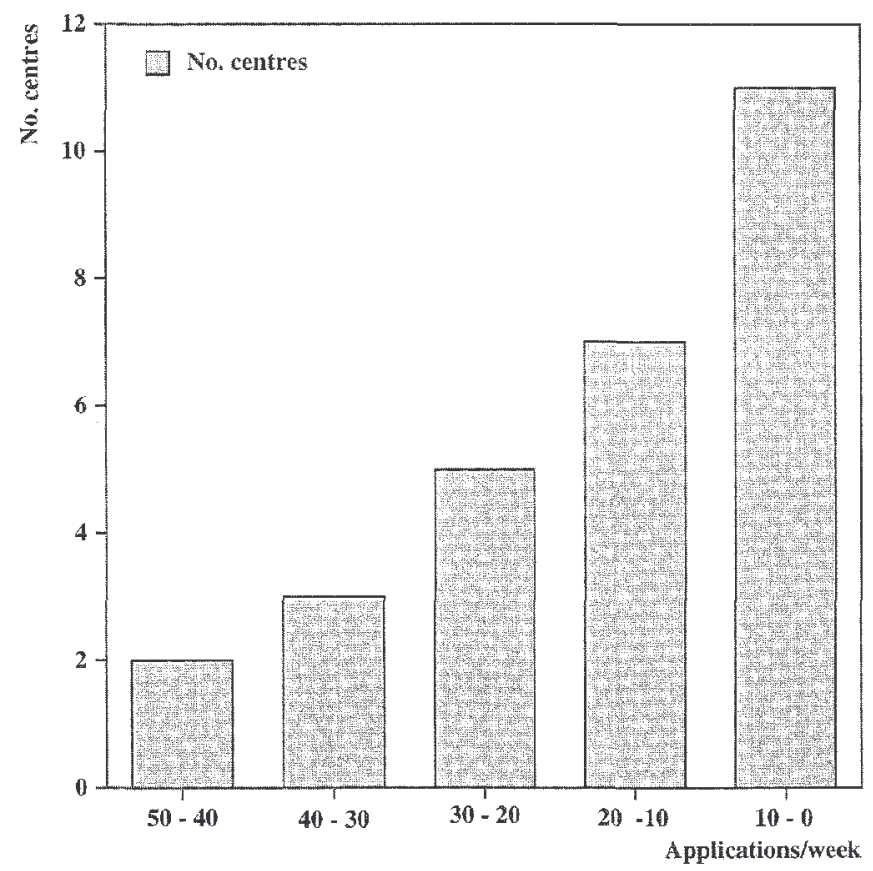

Fig. 6 Number of PET groups performing a number of applications per week

\section{Relevant toxicologies, and dosimetry data for the more frequently used PET radiopharmaceuticals}

Generally, PET RPs are administered with very small amounts of the parent compound and chemical impurities. Nevertheless, the concentration of the pharmaceutical itself, as well as the amounts of by-products and impurities, may be toxicologically relevant. Different production pathways may lead to very different concentrations of the radiopharmaceutical (i.e. the specific radioactivity may vary by several orders of magnitude) and to very different by-products and impurities. Although certain production pathways may be better than others from the standpoint of quality of the products, production and equipment parameters may necessitate (and therefore justify) the use of other production pathways. It must be emphasized that differences in the purity of these radiopharmaceuticals are acceptable as long as the maximum concentration of the material, its impurities and its byproducts are well below toxicologically relevant limits. In judging the extent of these limits it must be considered that all PET RPs are administered only on a few occasions in a subject's lifetime. More frequent administration is limited to follow-up studies in severe illnesses, where other risk factors become more important.

Impurities that may occur in the more frequently used PET RP preparations and their toxicological relevance are listed in Table 2. Some of these impurities need only be considered for certain production procedures. In this publication we discuss the relative toxicological importance of these compounds and provide information about available toxicological data.

An important aspect of the SPCs of a radiopharmaceutical is the dosimetry associated with its administration. Although ICRP publication 53 in combination with ICRP publication 60 already provides radiation dose estimates for most of the relevant PET RPs, recent investigations have shown that some of the data need to be reevaluated. A task group has been established within the "EU Concerted Action on PET Investigations to deal with the refined dosimetry calculations for PET RPs, which in particular should include the aspects of tracer kinetics. The dosimetry compilation as given in Table 3 is intended only as a summary of the current knowledge and should be sufficient for the safe handling and administration of these PET RPs, despite the need for refinements in the future. 
Table 2. Toxicologically relevant components

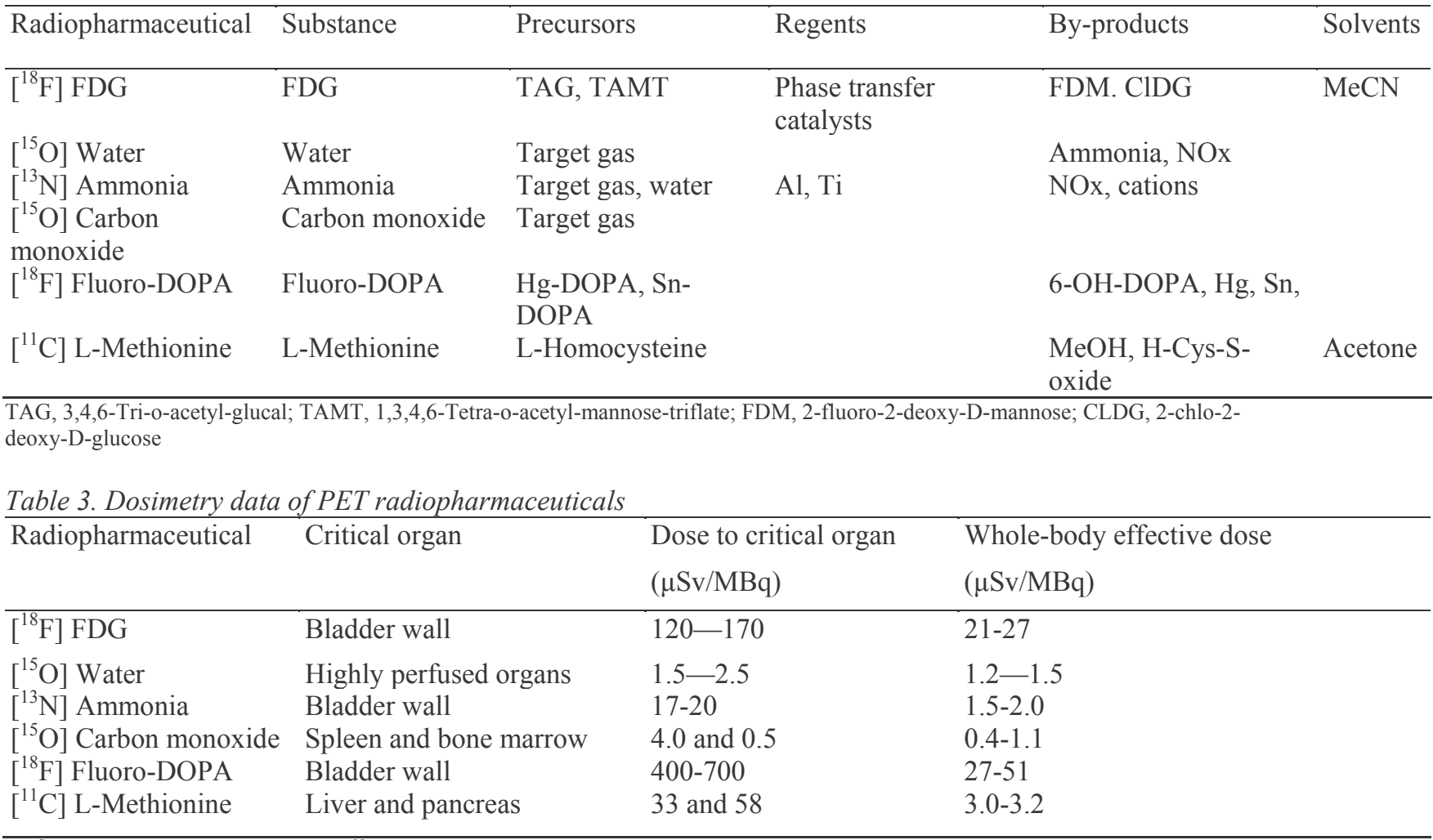

2-[is F]Fluбro-2-deoxy-D-glucose $\left(2-{ }^{18} F J F D G\right)$

\section{Products}

2-Fluoro-2-deoxy-D-glucose (FDG). The specific radioactivity of the final product will vary, depending on the reaction pathway (either nucleophilic or electrophilic substitution), from "no carrier added" (up to $1 \mathrm{TBq} / \mu \mathrm{mol}$ ) to low specific radioactivities (down to $20 \mathrm{GBq} / \mathrm{mmol}$ ). The amount of stable FDG administered in a study can therefore vary accordingly from less than $1 \mu \mathrm{g}$ to $4 \mathrm{mg}$. The latter amount may be considered significant from a toxicological standpoint. However, use of this low specific radioactivity material in animal studies showed no toxicity at 150 times the human dose range in dogs and at 3000 times the human dose range in mice, each over 3 weeks. $[2,3]$.

Several thousand applications of 2- $\left[{ }^{18} \mathrm{~F}\right]$ FDG with a low specific radioactivity have been performed to date. However, not a single case of an adverse reaction has been reported which could possibly be related to any toxicological effect.

2-Fluoro-2-deoxy-D-mannose (FDM). While some formerly used electrophilic substitution reactions lead to a poor stcreospecific addition, which results in a contamination of FDG with up to $30 \%$ FDM most currently employed electrophilic reaction pathways lead to a much smaller FDM contamination in the range of TPIo-5\% only [4]. It has been shown, however, that biochemically FDM and FDG follow the same biokinetics [5]. Accordingly, FDM contamination does not influence the diagnostic value of the radiopharmaceutical. FDM has not been tested in toxicological studies so far. Form the known similarity of the biochemical and biokinetical behaviour it can be assumed that up to 30\% contamination of FDG with FDM is of no toxicological significance. Nearly all FDG applications performed in the years from 1980 to 1985 (several hundred) were contaminated with up to $30 \%$ FDM. No toxicologically relevant adverse effects were reported in those years either.

Precursors

3,4,6-Tri-O-acetyl-glucal (TAG). Complete hydrolysis of the precursor used in the electrophilic substitution reaction leads to deoxy-D-glucose, which is of no toxicological significance. However, partial hydrolysis leads to a mixture of acetylated deoxy-glucose isomers, which have not been studied for any toxicological effects. The amount of this mixture varies from $0.5 \%$ to $5 \%$ of the precursor. Considering a starting inventory of about $60 \mathrm{mg}$ TAG, this may amount to ca. $3 \mathrm{mg}$ of the byproducts in one synthetic batch. However, the use of reverse phase 
cartridges (since 1987) has reduced the amount of partially hydrolysed precursor in the end product to values below $0.5 \%$ (less than $0.5 \mathrm{mg}$ ). Nearly all the FDG studies before the introduction of reversed phase cartridges contained about $2 \%$ partially hydrolysed precursor, but no toxicologically relevant adverse effects were reported in those years.

1,3,4,6.ti-Tetra-O-aceiyl-l-O-trifluormethane-sulphonyl- $\beta$-D-manno-pyranose. Complete hydrolysis of this precursor, which is used in the nucleophilic synthesis, leads to D-glucose. Partial hydrolysis leads to a mixture of acetylated glucose isomers, ranging from $0.2 \%$ to $2 \%$. Since the amount of starting material is about 3 times less than in clectrophilic substitution reactions $(20 \mathrm{mg})$, the amount of these materials is in the $\mu \mathrm{g}$ range. This is assumed to have no toxicological significance, especially given the experience with syntheses using TAG as a precursor.

\section{By-products}

2-Chloro-2-deoxy-D-glucose (ClDG). In some nucleo-philic syntheses the use of hydrochloric acid for the hydrolysis of the protected sugar may lead to the formation of 2-chloro-2'-deoxyglucose. As the amount of this byproduct is in the $\mu \mathrm{g}$ range, its detection requires sophisticated detector systems. At this concentration the amount of CIDG has not been considered toxicologically relevant, especially in view of the amounts of FDG tolerated in the electrophilic synthesis production. However, detailed investigations of the toxicity of CIDG and a comparison of its possible toxicity with that of FDG have not yet been carried out. By using other mineral acids or sodium hydroxide for the hydrolysis of the precursors formation of CIDG can be avoided [6].

\section{Catalysts and reagents}

Kryptofix 2.2.2. The toxicity of the phase transfer catalyst 1,10 diaza-7,7,13,16,21,24-hexaoxabicyclo[8.8.8]hexacosan (Kryptofix 2.2.2), used in some nucleophilic syntheses, has been reported to be significant, with $\mathrm{LD}_{50}$ levels of $35 \mathrm{mg} / \mathrm{kg}$ (i.v.) in rats [7]. However, rats that received up to $188 \mathrm{mg} / \mathrm{kg}$ in acute toxicity studies showed no histopathological lesions and only transiently increased levels of the liver enzymes GOT and GPT [8]. The compound has been considered as a therapeutic complexing agent in severe internal contamination with cationic radionuclides, such as ${ }^{90} \mathrm{Sr}$, and based on animal excretion data, the therapeutic doses considered for humans were in the range of $18-35 \mathrm{mg} / \mathrm{kg}$ [9]. In $2-\left[{ }^{18} \mathrm{~F}\right] \mathrm{FDG}$ preparations the cryptand can be removed from the reaction solution by a cation exchange resin cartridge, mounted in-line with $\mathrm{C}$-18 reversed-phase cartridges used for the removal of partially hydrolysed precursor. Simple test procedures for the cyptand allow for the detection of $0.025 \mathrm{mg} / \mathrm{ml}$. It has been recommended that the maximum allowable concentration for $2-\left[{ }^{18} \mathrm{~F}\right] \mathrm{FDG}$ preparations should be $0.22 \mathrm{mg} / \mathrm{ml}$, with a limit, of max. $10 \mathrm{ml}$ [10].

Tetra-alkylammonium salts. No recent toxicological data on tctra-butylammonium salts are available in the open literature; however, an old reference states an $\mathrm{LD}_{0}$ of $19 \mathrm{mg} / \mathrm{kg}$ subcutaneous! ' ' administered to rats [H].

According to RTECS more recent data have been reported by the U.S. Army Armament Research \& Development Command, stating an $\mathrm{LD}_{50}$ value of $10 \mathrm{mg} / \mathrm{kg}$ (i.v.) in mice. This implies that the toxicity of tetrabutylammo-nium salts is about fourfold that of Kryptofix 2.2.2.

4-(4-Melhyl-7-piperinidyl)-pyridine (4-MPP). The stationary bound catalyst 4 -MPP is considered to be a toxic material, which requires special precautions for handling. The material causes eye and skin irritations. This is underlined by an $\mathrm{LD}_{50}$ of $420 \mathrm{mg} / \mathrm{kg}$ on dermal exposure to rabbits. An $\mathrm{LD}_{50}$ of $160 \mathrm{mg} / \mathrm{kg}$ for oral ingestion in rats has also been reported. Although it is unlikely that the stationary bound catalyst will leak from its support material, the absence of 4 -MPP in the end product should be verified by an analytical technique, such as UVspcctrophotometry.

\section{Solvents}

Acetonitrile. Residual organic solvents used in the synthesis may be carried through into the end product, especially with the nucleophilic syntheses. The most critical solvent is acetonitrile, which is considered toxic $\left(\mathrm{LD}_{50}\right.$ rat orally: $3800 \mathrm{mg} / \mathrm{kg}$ ). Guidelines are currently being established by the European Pharmacopoeia Commission [PA/PH/SG (94) 143], who propose a limit for ace-tonitrile of $50 \mathrm{ppm}$ in pharmaceuticals with a maximum daily intake of $1.28 \mathrm{mg} /$ day [I]. For drugs and pharmaceuticals which are not used or applied chronically, the limits can be tripled. These guidelines allow an uncomplicated handling of the solvent problem in $2-\left[{ }^{18} \mathrm{~F}\right] \mathrm{FDG}$ syntheses, since it is unlikely that these limits will be exceeded in any routine production. Acetone. Of the solvents used ito clean the synthesis apparatus, acetone is used most frequently. Acetone is considered to be of minimal concern, and a limit for its content in pharmaceuticals has not been established $\left(\mathrm{LD}_{50}\right.$ rat orally: $101300 \mathrm{mg} / \mathrm{kg}$ ). For non-chronically applied drugs the limit would be in the $0.1 \%$ range. 


\section{Dosimetry}

The dosimetry for 2-[ $\left.{ }^{18} \mathrm{~F}\right]$ FDG has been generally estimated according to the MIRD concept by several authors $[2,3,12,13]$. Despite its relative long history of clinical use, relatively few accurate measurements of its dosimetry have been carried out, however. Therefore, it would be highly desirable to have more accurate measurements based on dynamic whole-body PET investigations. Radiation dose estimates from before 1990 $[14,15]$ are smaller by a factor of 2 , compared with the current dose estimates, which include the tissue weighting factors suggested by ICRP publication 60 [16]. Most of the remaining variations reported in the recent literature stem from different estimates and/or suggestions on when patients should void their bladder [17-19]. Critical organ. The critical organ is the bladder wall. The reported radiation dose to the bladder wall is between 120 and $170 \mu \mathrm{Sv} / \mathrm{MBq}(32-46 \mathrm{mrem} / \mathrm{mCi})$.

Whole-body effective dose. The whole-body effective dose is reported to be $21-27 \mu \mathrm{Sv} / \mathrm{MBq}(80-100$ $\mathrm{mrem} / \mathrm{mCi}$ ).

[s OJWater Product

The product is an unaltered physiological substrate with no toxicological relevance in the amounts considered for applications in PET.

\section{Precursors}

Target gases. Different production pathways may use different precursors, and these may come into contact with the end product. Precursors and starting materials are usually analytical grade gas mixtures of either ca. 99\% nitrogen containing ca. $1 \%$ oxygen or ca. $95 \%$ nitrogen with ca. $5 \%$ hydrogen. Both mixtures are of no toxicological relevance to the end product.

By-products

Oxides of nitrogen. Using nitrogen gas with $0.5 \%-2 \%$ of molecular oxygen results in the formation of oxides of nitrogen in the target gas. These must be removed from the precursor before the catalytic oxidation of hydrogen to prevent the formation of nitrates in the final product. Besides the toxicological concern, these by-products constitute radiochemical impurities. Absorption on a combination of charcoal and soda lime is a useful method to remove these impurities. Their absence can be monitored by gas chromatography or by photometrical verification of the absence of nitrates in the final product. Both methods require test productions directly before the production for human application. However, at the concentrations in question, nitrates formed are of no toxicological relevance [20] [sodium nitrate: $\mathrm{LD}_{50}$ rabbit (oral) $2 \mathrm{~g} / \mathrm{kg}$, The Merck Index Ref. 8598], Ammonia, hydrazine. It has been postulated that ammonia and hydrazine might be formed during the catalytic oxidation of hydrogen on the palladium catalyst. However, their formation has not been observed by any of the routine producers. Especially the formation of hydrazine is extremely unlikely, unless the level of ammonia is very high. The toxicity of hydrazine is well documented [20] [LD $\mathrm{LD}_{50}$ mice (i.v.) $57 \mathrm{mg} / \mathrm{kg}$, The Merck Index Ref. 4691]. The absence of ammonia formation is checked and controlled by $\mathrm{pH}$ measurement of the end product. The use of nitrogen gas with ca. 5\% hydrogen may result in the formation of ammonia directly in the target. As already stated, the absence of ammonia can be checked and controlled by $\mathrm{pH}$ measurement of the end product. At tolerable $\mathrm{pH}$ levels up to 7.5, the ammonia content is of no toxicological relevance [20] [e.g. ammonium chloride: $\mathrm{LD}_{50}$ rats (i.v.) $30 \mathrm{mg} / \mathrm{kg}$, The Merck Index Ref. 531].

Catalysts and reagents

Palladium catalysts are of no toxicological relevance to the end product. Solvents

Physiological saline $(0.9 \%)$ is of no toxicological relevance to the end product.

\section{Dosimetry}

Initial calculations of the absorbed dose after the injection of $\left[{ }^{15} \mathrm{O}\right]$ water have been based on an instantaneous equilibration of the applied dose to the whole body L14, 21-23]. Fresh calculations have included the circulation behaviour of a bolus of $\left[{ }^{15} \mathrm{O}\right]$ water, considering the perfusion of individual organs $[24,25]$. This model has led to an increase of the dose to highly perfused organs by a factor of 2, when compared with the dose estimates based on the instant equilibration model.

Critical organ. There is no special critical organ for $\mathrm{f}^{15} \mathrm{OJ}$ water, due to its free diffusibility. In other terms, all highly perfused organs such as the heart, brain, and kidneys can be regarded as critical organs. The dose to these 
organs is $1.5-2.5 \mu \mathrm{Sv} / \mathrm{MBq}$.

Whole-body effective dose. The whole-body effective dose has been calculated to be $1.24 \mu \mathrm{Sv} / \mathrm{MBq}$.

$\left[{ }^{13} \mathrm{~N}\right]$ Ammonia Product

At a "no-carrier-added" concentration level the product is an unaltered physiological substrate. At the amount considered for applications in PET it is of no toxicological relevance.

Precursors

The precursor is either ultrapure water or a water-ethanol mixture with an ethanol content of $5 \mathrm{ppm}$. This ethanol concentration is of no toxicological significance.

By-products

Metal cations. Direct in-target production may lead to impurities stemming from corrosive processes at the target-body and the target-foil (e.g. metal hydroxides). The amount, and composition of these metals vary with the type of material used for the target construction. Metal cations can be quantitatively removed from the raw product by chromatographic techniques, such as absorption on cation exchange resins. Ammonia can then be cluted specifically before the metal cations.

The absence of nickel cations from nickel targets can be monitored by spectrophotometric methods (e.g. The Merck Spektroquant). A level of less than $1 \mathrm{ppm}$ is usually observed. This equals a maximum dose of $20 \mu \mathrm{g}$ in a typical injection volume of $20 \mathrm{ml}$. $L D_{50}$ values (dogs, i.v.) for nickel salts have been reported to be in the order of $50 \mathrm{mg} / \mathrm{kg}$ [20] (The Merck Index Ref. 6412).

Catalysts and Reagents

Metal cations. The reaction of $\left[{ }^{13} \mathrm{~N}\right]$ nitrates with Dev-arda's alloy or titanium (III) chloride solution in water and the subsequent distillation of $\left[{ }^{13} \mathrm{~N}\right]$ ammonia is considered to be free of by-product formation. Care must be taken, however, to guarantee the absence of traces of these reagents or parts of their decomposition in the end product. Aluminium and titanium can be detected very sensitively by spectrophotometric methods and levels of less than $1 \mathrm{ppm}$, which are usually observed, are considered to be of no toxicological relevance.

Solvents

Physiological saline $(0.9 \%)$ is of no toxicological relevance to the end product.

Dosimetry

Few publications have dealt with the dosimetry of $\left.1^{13} \mathrm{~N}\right]$ ammonia so far $[14,19,26]$.

Critical organ. The critical organ is the bladder wall. The dose is calculated to be $18.5 \mu \mathrm{Sv} / \mathrm{MBq}$.

Whole-body effective dose. The whole-body effective dose has been calculated to be 1.5-2.0 $\mu \mathrm{Sv} / \mathrm{MBq}$.

$l^{15} \mathrm{O}$ Carbon monoxide Product

The toxicity of carbon monoxide is well documented. Unfortunately, $\left[{ }^{15} \mathrm{O}\right]$ carbon monoxide cannot be produced in the "carrier-free" or "no-carrier-added" state, and it is therefore essential to carefully control the concentration level. It is generally acknowledged that $10 \% \mathrm{HbCO}$ is tolerated without clinical symptoms [27]. This $\mathrm{HbCO}$ level is reached after an 8 -h exposure to $\mathrm{CO}$ at a concentration of $0.01 \%$ or after a 10 -min exposure to a $\mathrm{CO}$ concentration of $0.1 \%$. A level of $0.025 \%$ has been suggested to be safe in continuous inhalation experiments., where the protocol is limited to $15 \mathrm{~min}$ [28]. The concentration of CO can be controlled by gas chromatography or by IR absorption.

\section{Precursors}

Target gases. The precursor and starting material is usually an analytical grade gas mixture in the range of $99.5 \%-99.75 \%$ nitrogen and $0.25 \%-0.5 \%$ oxygen. It is of no toxicological relevance to the end product. By-products

Oxydes of nitrogen. Using nitrogen gas with $0.25 \%-0.5 \%$ of molecular oxygen results in the formation of oxides of nitrogen in the target gas. Absorption on a combination of charcoal and soda lime is a useful method to remove these by-products before the final product is formed catalytically. Their absence can be monitored by gas chromatography [28].

Catalysts and reagents

The charcoal catalyst is usually heated to $1000^{\circ} \mathrm{C}$, so care should be taken that this does not leak degradation 
products like tar or particulates. This can be checked by filter systems, which can be inspected visually (Clark et al. 1987).

\section{Dosimetry}

Various calculations for the absorbed radiation dose from $\left[{ }^{15} 0\right]$ carbon monoxide administration have been published, the values obtained being dependent on the protocol of the tracer administration [14, 16]. Initial studies favoured continuous inhalation [21,23]. With the introduction of new camera systems and fast computers for handling the data of dynamic aquisition protocols, single-breath inhalation applications have also been used. The dose calculations vary accordingly $[15,19]$.

Critical organ. The critical organ is the spleen and the bone marrow. It has been estimated that they receive doses of 4.0 and $0.5 \mu \mathrm{Sv} / \mathrm{MBq}$, respectively.

Whole-body effective dose. The whole-body effective dose has been calculated to be $0.4-1.1 \mu \mathrm{Sv} / \mathrm{MBq}$. I-6- $\left[{ }^{18}\right.$ F] Fluoro-DOPA Product

6-Fluoro-DOPA has not been investigated in toxicological studies so far. After initial testing in rodents and primates, the radiopharmaceutical L-6- $\left[{ }^{[8}\right.$ F]fluoro-DOPA has been used since 1987, both in Europe and in North America, with a specific radioactivity of about $4 \mathrm{GBq} / \mathrm{mmol}$ in several hundred human studies. From this experience, with no reported adverse reaction, it can be stated that human dose levels of $0.5 \mathrm{mg}(\mathrm{ca} .10 \mu \mathrm{g} / \mathrm{kg}$ ) seem to be toxicologically safe.

\section{Precursors}

Different production pathways make use of different precursors.

Radiofluorodemercuration procedures may give rise to mercury breakthrough and careful control of possible mercury contamination of the injectable preparation is mandatory. By following the recommendations for the radiosynthesis given in a review by Luxen et al. [29], levels of mercury below 20 ppb can be expected. Such a concentration in a typical injection volume of $10 \mathrm{mi}$ would lead to a dose of $3 \mathrm{ng} / \mathrm{kg}$ in a $70-\mathrm{kg}$ subject, a value which is far below the smallest toxic dose of $5 \mathrm{mg} / \mathrm{kg}$ appearing in estimations of the toxicology of mercury [30]. Mercury in food has been limited to $0.5 \mathrm{mg} / \mathrm{kg}$ in fish and $0.05 \mathrm{mg} / \mathrm{kg}$ in other food by the WHO. German BAT values (Biologische Arbeitsstoff Toleranz) for chronic mercury intake have been limited to $100 \mu \mathrm{g} / 1$ for whole blood [31], and the United States Pharmacopoeia] Convention [32] has proposed that mercury content should be less than $0.5 \mu \mathrm{g} / \mathrm{ml}$ in L-6- $\left[{ }^{18} \mathrm{~F}\right]$ fluoro-DOPA preparations. Tn view of these data it can be expected that mercury breakthrough in L-6- $\left[{ }^{18} \mathrm{~F}\right]$ fluoro-DOPA preparations is of no significance from a toxicological standpoint. Spectrophotometric tests using chelating agents are not sensitive enough to detect these low concentrations (detection limit $>5$ ppin). However, ionic mercury levels can be measured using an HPLC method based on reverse phase ion-pair chromatography which is reported to detect ionic mercury down to $10 \mathrm{ppb}$ [33], Alternatively, a simple purification method based on Chelex-S resin for demercuration has been reported [34]. The nucleophilic synthetic pathway using radioflu-orodestannylation avoids the mercury problem [35]. The possible contamination by decomposition products is avoided by HPLC work-up of the end product.

By-products

L-DOPA and L-6-hydroxy-DOPA are the main possible by-products, depending on the synthesis employed. L-6Hydroxy-DOPA is converted into the potent neurotoxin, L-6-hydroxydopamine in vivo [36J and $50 \mu \mathrm{g}$ has been suggested as the upper acceptable limit for L-6-hydroxy-DOPA in any single injected dose [37]. L-DOPA and D, L-6-hydroxy-DOPA reference materials are available commercially.

\section{Dosimetry}

Dosimetry data for L-6-L ${ }^{18}$ F]fluoro-DOPA are difficult to find in the literature $[14,15,38]$. Reported values vary by almost a factor of 2 due in part to different estimates for the mean body residence time. A recent paper [39] states that early voiding of the bladder reduces the absorbed dose significantly.

Critical organ. The critical organ is the bladder wall, which receives a dose in the order of $400-700 \mu \mathrm{Sv} / \mathrm{MBq}$. Whole-body effective dose. The whole-body effective dose is reported to be

${ }^{11}$ C-labelled L-Methionine Product

The product is an unaltered physiological substrate with no toxicological relevance in the amounts considered for applications in PET. The usual concentration at a "no carrier added" level is in the order of $10 \mathrm{nmol} / \mathrm{ml}$ with ca. 2-6 ml injection volume. 


\section{Precursors}

The precursor used in the preparation of ${ }^{11} \mathrm{C}$-L-methio-ninc is L.-homocysteine. It is a physiological substrate with no toxicological relevance at the amount used for the production of ${ }^{11} \mathrm{C}$-L-methionine (i.e. $15 \mathrm{mg}$ ). About $90 \%$ of the precursor is separated from the product during the work-up procedure. The radioactive precursor is "no carrier added" $\left[{ }^{11} \mathrm{C}\right]$ iodomethanc. It can be separated from the end product quantitatively.

By-products

Sulphoxide derivatives of methionine and homocysteine can be formed during the preparation, as well as methanol. Of these by-products only homocysteine sulphoxide may form in amounts larger than "no-carrier added". No toxicity data are available for this compound. However, all three by-products are efficiently separated from the end product during the HPLC work-up procedure. An analytical chromatogramme can serve as proof for the absence of these by-products.

Catalysts and reagents

Hydroiodic acid is the only reagent that has to be considered. It is neutralized with sodium hydroxide before the labelling reaction is carried out.

Solvents

It is conceivable that acetone can be carried over into the end product. Its concentration after an HPLC work-up is generally far below any toxicologically relevant level.

Dosimetry

Most of the listed dosimetry estimates for ${ }^{11} \mathrm{C}$-L-methio-nine are based on relatively old data $[14,15,40]$. Critical organ. The critical organs are the liver and the pancreas which receive doses in the order of 33 and $58 " \mu \mathrm{Sv} / \mathrm{MBq}$, respectively.

Whole-body effective dose. The whole-body effective dose is reported to be in the range of $3.1 \mu \mathrm{Sv} / \mathrm{MBq}$.

\section{Acknowledgements}

The authors arc indebted to all PET users who responded to the questionnaire. Without their help, this compilation would not have been possible. The authors thank Dr. A. Bossmann, Bundesinstitut f. Arzeimittcl und Mcdizinprodukte, Berlin, and PD. Dr. H. Hcrzog, Forschungsanlage Jiilich for attending and helping the Task Group in discussions on toxicology and dosimetry. The financial support of the Task Group by the EANM is gratefully acknowledged.

\section{References}

[1] European Pharmacopoeia Commission. Guideline for residual solvent levels in drug substances and excipients used for the preparation of medicinal products. Document (PA/PH/SG (94) 143).

[2] Som P, Atkins HL, Bandoypadhyay D, et al. J Nuc.L Med 1980; 21:670—675.

[3] Reivich M, Kuhl D, Wolf A, et al. The [ $\left.{ }^{18} \mathrm{~F}\right]-$ fluorodeoxyglu-cose method for the measurement of local cerebral glucose metabolism in man. Circ Res 1979; 44: 127-133.

[4] Bida GT, Satyamurthy N, Barrio J. The synthesis of 2-[F-18]Fluoro-2-deoxy-D-glucose using glucals: a reexamination. J Nucl Med 1984; 25: 1327-1334.

[5] Wienhard K, Pawlik G, Nebeling B, et al. J Cereb Blvvd Flow Metab 1991; 11:485-491.

[6] Fiichtner F, Steinbach J, Mâding P, Johannsen B. Basic hydrolysis of 2-[ $\left.{ }^{18} \mathrm{~F}\right]$ fluoro-1,3,4,6-tetra O-acetylD-glucose in the preparation of 2-[ ${ }^{18}$ F]fluoro-2-deoxy-D-glucose. Appl. Radiat Isot 1995; in press.

[7] Baudot P, Jaquc M, Robin M. Effect of a diaza-polyoxa-macr-obicyclic complexing agent on the urinary elimination of lead in lead-poisoned rats. Toxicol Appl Pharmacol 1977; 41: 113-115.

[8] Baumann M, Schâfcr E, Grein H. Short-term studies with the cryptating agent hexaoxa-diaza-bicyclohexacosane in rats. Arch Toxical 1984; 55 Suppl 7: 427-429.

[9] Müller WH, Beaumatin J. Distribution of a cryptating agent in excreta and its influence on urinary elimination of $\mathrm{Na}, \mathrm{K}, \mathrm{Mg}$. Ca, and $\mathrm{Zn}$ in the rat. Life Sci 1976; 17:1815-1820.

[10] Meyer G-J, Coenen HH, Waters SL, et al. Quality assurance and quality control of short-lived radiopharmaceuticals for PFT. In Stôcklin G, Pike V, cds. Radiopharmaceuticals for positron emission 
tomography: methodological aspects. Dordrecht Boston London: Kluwer Academic; 1993: 91-150.

[11] Hunt R. Some effects of quarternary ammonium compounds on the autonomic nervous system. $J$ Pharmacol Exp Ther 1926; 28: 367-388.

[12] Jones SC, Alavi A, Christman D, et al. The radiation dosimetry of 2-[F-18]fluoro 2-deoxy-D-glucose. ./ Nucl Med 1982; 23:613-617.

[13] Mejia AA, Nakamura T, Masatoshi I, et al. Estimation of absorbed doses in humans due to intravenous administration of fluorine-18-fluorodeoxyglucose in PET studies. J Nucl Med 1991; 32: 699-706.

[14] ICRP publication 53. Radiation dose to patients from radiopharmaceuticals. Oxford: Pergamon, 1988.

[15] Junker D, Fitschen J. Spezielle Probleme des Strahien-schutzes. In: Hundeshagen H, ed. Handbuch der Medizin. Ra-diologie vol 15/lb, Heidelberg Berlin New York: Springer, 1988: pp 119-147.

[16] ICRP publication 601990 recommendations of the international commission on radiological protection. Oxford: Perga-mon, 1991.

[17] Dowd MT, Chen C-T, Wendel MJ, ct al. Radition dose to the bladder wall from 2-[18F]fluoro-2-deoxy-Dglucose in adult humans. $J$ Nucl Med 1991; 32: 707-712.

[18] Huda W, Sandison G A. Estimates of the effective dose equivalent $\mathrm{H}_{\mathrm{E}}$, in positron emission tomography studies. Eur J Nucl Med 1990; 17: 116-120.

[19] Joharmsson L, Matisson S, Nosslin B, Leide-Svegborn S. Effective dose from radiopharmaceuticals. Eur J Nucl Med 1992: 19: 933-938.

[20] The Merck Index, 11th edn.Rahway N.J.: Merck; 1989.

[21] Kcarfott KJ, Absorbed dose estimates for positron emission tomography (PFT): $\mathrm{C}^{\mathrm{I}} \mathrm{O},{ }^{11} \mathrm{CO}, \mathrm{CO}^{15} \mathrm{O} \mathrm{J} \mathrm{Nucl}$ Med 1982; 23: 1031-1037.

[22] Kearfott KJ, Rottenberg DA, Volpe BT. Design of steady-state PET protocols for ncurobchavioural studies: $\mathrm{CO}^{15} \mathrm{O}$ and ${ }^{19} \mathrm{Ne}$. J Comput Assist Tomogr 1983; 7: 51-57.

[23] Bigler RE, Sgouros G. Biological analysis and dosimetry of ${ }^{15} \mathrm{O}$-labelled $\mathrm{O}_{2}$ : $\mathrm{CO}_{2}$, and $\mathrm{CO}$ gases administered continuously by inhalation../ Nucl Med 1983; 24: 431-437.

[24] Smith T, Tong C, Lammcrtsma AA, ct al. Dosimetry of intravenously administered oxygen 15 labelled water in man: a model based on experimental human data from 21 subjects. Eur J Nucl Med 1994; 21: 11261134.

[25] Brihaye C, Depresseux JC, Comar D. Radiation dosimetry for bolus administration of oxygen-15-water. J Nucl Med 1995; 36:651-656.

[26] Lockwood AH. Absorbed doses of radiation after an intravenous injection of N-13 ammonia in man: concise communication. ./ Nucl Med 1980; 21: 276-278.

[27] Forth W, Henschler D, Rummel W, eds. Allgemeine and spezi-elle Pharmakologie und Toxikologie. Zurich: Bibliographisches InstiUit, 1987.

[28] Clark JC, Crouzel C, Meyer G-J, et al. Current methodology for oxygen-15 production for clinical use. Appl Radial hot 1987; 38: 597-600.

[29] Luxen A, Perlmutter M, Bida GT, ct al. Remote semiautomat-ed production of 6- $\left[{ }^{18}\right.$ F]Fluoro-L-DOPA. for human studies with PFT. Appl Radial hot 1990; 41: 275-281.

[30] Seller HG, Sigel H. Handbook of toxicity of inorganic compounds. New York: Marcel Dekker; 1988.

[31] Deutsche Forschungsgcmcinschaft. BAT Werte DFG, 1994.

[32] United Slates Pharmacopoeial Convention. Fluorodopa F 18 injection. Pharmacopoeia/ Forum 1991; 17: 1582-1584.

[33] Luxen $A$, Barrio JR, Van Moffaert G, et al. Remote semiauto-mated production of 6- $\left[{ }^{18} \mathrm{~F}\right]$ fiuoro-L-DOPA for human studies with PET. J Labelled Comp Radiopharm 1988; 26: 465-466.

[34] Wagner R. Removal of mercury contamination from 6-F-FDOPA preparations. J labelled Comp Radiopharni 1993; 32: 250.

[35] Lemaire C, Damhaut P, Plenevaux A, Comar D. Enantioselec-tive synthesis of 6-[fluorine-18]fluoro-LDOPA from no-carrier-added fluorine- 18-fluoride. J Nucl Med 1994; 35: 1996-2002.

[36] Sachs C, Jonsson G. Selective 6-hydroxy-DOPA induced degeneration of central and peripheral noradrenalin neurons. Brain Res 1972; 40: 563-568.

[37] Pike VW, Kenseti MJ, Turton DR, et al. Labelled agents for PFT studies of the dopaminergic system some quality assurance methods, experience and issues. Appl Radial hot 1990; 41:483-492.

[38] Harvey J, Firnau G, Garnctt ES. Estimation of the radiation dose in man due to 6-[ ${ }^{18}$ F]FIuOrO-L-DOPA. $J$ Nucl Med 1985; 26:931-935.

[39] Lu E, Meyer E, Kuwabara H, et al. Reduction of radiation absorbed dose in F-18-FDPOA PET studies by hydration induced voiding. J Nucl Med 1995; 36: 98.

[40] Hübner KF, Andrews GA, Buonocore E, et al. Carbon-11-Ia-belled amino acids lor the rectilinear and positron tomographic imaging of the human pancreas. J Nucl Med 1979; 20: 507-513. 